\title{
BRAIN AFFERENTS TO THE LATERAL CAUDAL VENTROLATERAL MEDULLA: A RETROGRADE AND ANTEROGRADE TRACING STUDY IN THE RAT
}

\begin{abstract}
A. COBOS, ${ }^{a, b}$ D. LIMA, ${ }^{a}$ A. ALMEIDA ${ }^{a, c}$ AND I. TAVARES ${ }^{a *}$

a Institute of Histology and Embryology, Faculdade de Medicina and IBMC, University of Oporto, Alameda Professor Hernâni Monteiro, 4200-319 Porto, Portugal

${ }^{b}$ Department of Morphological Sciences, Faculty of Medicine and Odontology, University of Santiago de Compostela, Santiago de Compostela, Spain

'Life and Health Sciences Research Institute, School of Health Sciences, University of Minho, Braga, Portugal
\end{abstract}

\begin{abstract}
The ventrolateral medulla (VLM) modulates autonomic functions, motor reactions and pain responses. The lateralmost part of the caudal VLM (VLMlat) was recently shown to be the VLM area responsible for pain modulation. In the present study, the brain sources of VLMlat afferent fibers were determined by tract-tracing techniques. Following injection of cholera toxin subunit B into the VLMlat, retrogradely labeled neurons in the forebrain occurred at the somatosensory, insular, motor, limbic and infralimbic cortices, and at the central amygdaloid nucleus. Retrogradely labeled neurons in diencephalic regions were observed in the lateral hypothalamus, posterior hypothalamus and paraventricular nucleus. In the brainstem, retrograde labeling occurred at the periaqueductal gray, red nucleus, parabrachial area, nucleus raphe magnus, nucleus tractus solitarii, lateral reticular nucleus and dorsal and ventral medullary reticular formation. In the cerebellum, retrogradely labeled neurons occurred at the lateral nucleus. Following injections of the anterograde tracer biotinylated dextran amine (BDA) into the lateral hypothalamus or paraventricular nucleus, anterogradely labeled fibers were mainly observed in the VLMlat. Injections of BDA into the periaqueductal gray, red nucleus or lateral nucleus of the cerebellum resulted in anterograde labeling in the VLMlat and lateral reticular nucleus.
\end{abstract}

The present study gives an account of the brain regions

${ }^{*}$ Corresponding author. Tel: +351-22-509-1468; fax: +351-22-5505728.

E-mail address: isatav@med.up.pt (I. Tavares).

Abbreviations: $\mathrm{ABC}$, avidin-biotin complex; BDA, biotinylated dextran amine; BST, bed nucleus of the stria terminalis; CeA, central amygdaloid nucleus; CTb, cholera toxin subunit B; CVLM, caudal ventrolateral medulla; DAB, diaminobenzidine tetrahydrochloride; DRt, dorsal reticular nucleus; IC, insular cortex; IL, infralimbic cortex; IO, inferior olive; KF, Kölliker-Fuse nucleus; Lat, lateral (dentate) cerebellar nucleus; LC, locus coeruleus; LH, lateral hypothalamic area; LRt, lateral reticular nucleus; $M_{1}$, primary motor cortex; $M_{2}$, secondary motor cortex; $\mathrm{Pa}$, paraventricular hypothalamic nucleus; PAG, lateral periaqueductal gray; $\mathrm{PB}$, phosphate buffer; PBS, phosphate-buffered saline; PBST, phosphate-buffered saline containing $0.5 \%$ Triton $\mathrm{X}-100$; $\mathrm{PRL}$, prelimbic cortex; $\mathrm{R}$, red nucleus; $\mathrm{RMg}$, raphe magnus nucleus; RVLM, rostral ventrolateral medulla; SO, superior olive; Sol, nucleus tractus solitarii; $\mathrm{Sp}_{5} \mathrm{C}$, spinal trigeminal nucleus; pars caudalis, VLM, caudal ventrolateral medulla; VLMlat, lateralmost part of the caudal ventrolateral medulla; VLPAG, ventrolateral periaqueductal gray; VRt, ventral reticular nucleus. putatively involved in triggering the modulatory actions elicited from the VLMlat. These include areas committed to somatosensory processing, autonomic control, somatic and visceral motor activity and affective reactions. The findings suggest that the VLMlat may play a major homeostatic role in the integration of nociception with other brain functions. (c) 2003 IBRO. Published by Elsevier Science Ltd. All rights reserved.

Key words: pain modulation, motor control, cardiovascular regulation, cholera toxin subunit $\mathrm{B}$, biotinylated dextran amine.

The ventrolateral medulla (VLM) is a functionally complex and heterogeneous brain area. The regulation of cardiovascular and respiratory functions is among the main autonomic functions performed by the VLM. The rostral VLM (RVLM) exerts vasopression through bulbospinal adrenergic neurons of the $\mathrm{C}_{1}$ adrenergic cell group, present in the RVLM (Willette et al., 1983; Kalia et al., 1985; reviewed by Chalmers and Pilowski, 1991). The caudal VLM (CVLM) exerts vasodepression and contains the $A_{1}$ noradrenergic cell group (Day et al., 1983; Willette et al., 1983; Kalia et al., 1985; Murugaian et al., 1989; reviewed by Chalmers and Pilowski, 1991). The RVLM also contains most of the VLM respiratory neurons (Saper, 1995). The VLM participates in motor control through cerebellar and rubral connections of the lateral reticular nucleus (LRt; Alstermark et al., 1981; Clendenin et al., 1974; Ekerot, 1989), located at the CVLM. Pain control from the VLM is elicited from the CVLM, which is one important component of the endogenous pain modulatory system (Gebhart and Ossipov, 1986; Sotgiu, 1986; Janss and Gebhart, 1987, 1988; Liu and Zhao, 1992; reviewed by Tavares and Lima, 2002). The analgesia produced by CVLM stimulation is more profound and long-lasting than that obtained from other pain control centers (Satoh et al., 1983; Jensen and Yaksh, 1984; Carstens and Watkins, 1986; Jones and Gebhart, 1986a,b; Ness and Gebhart, 1987). At the CVLM, the reticular formation located between the LRt and the spinal trigeminal nucleus, pars caudalis $\left(\mathrm{Sp}_{5} \mathrm{C}\right)$, is the area specially devoted to pain modulation (reviewed by Tavares and Lima, 2002). This area of the CVLM, which has been named lateralmost part of the caudal ventrolateral medulla (VLMlat), is located ventrolaterally to the $A_{1}$ noradrenergic cell group (Tavares et al., 1996, 1997a) and projects exclusively to spinal cord layers involved in the transmission of nociceptive information (Tavares and Lima, 1994; Tavares et al., 1998; reviewed by Tavares and Lima, 2002). Furthermore, the electrical threshold necessary to produce 
analgesia from the VLMlat is lower than in the other CVLM areas (Gebhart and Ossipov, 1986). Finally, the VLMlat contains neurons that are the source of a dysynaptic pathway relayed in the noradrenergic pontine $A_{5}$ area, which conveys the spinal $\alpha_{2}$-adrenoreceptor-mediated analgesia elicited from the VLM (Tavares et al., 1996, 1997a).

Integration of autonomic functions, motor control and pain modulation is crucial to body homeostasis, namely in life-threatening conditions (Spyer, 1989; Lovick, 1993; Harris, 1996). All those functions are played by the VLM, although somewhat segregated within this region. For example, the VLMlat, which is the pain region of the CVLM, is lateral to the cardiovascular region described by Blessing and $\mathrm{Li}$ (1989). It is possible that the VLM participates in the overall integration of inputs triggered in several areas of the CNS. In order to characterize the input arriving to the VLMlat it is important to map the afferents to this region. However, CNS projections to the CVLM have not been described as part of the thorough studies of projections from the spinal cord (Menétrey et al., 1983; Lima and Coimbra, 1991; Lima et al., 1991; Rajakumar et al., 1992; Ruigrok and Cella, 1995; Koekoek and Ruigrok, 1995). This study describes the brain regions that project to the VLMlat in the rat by retrograde tracing with cholera toxin subunit $B(C T b)$ complemented with anterograde tracing with biotinylated dextran amine (BDA).

\section{EXPERIMENTAL PROCEDURES}

Male Wistar rats from the Gulbenkian Institute of Science (Portugal), 285-305 g in weight, were used. The experiments followed the regulations of local authorities for handling laboratory animals and the European Communities Council Directive 86/609/EEC. All efforts were made to minimize the numbers of animals used in the experiments and to avoid suffering.

\section{Retrograde tracing studies}

Fourteen rats were anesthetized with a gaseous mixture of halothane ( $4 \%$ for induction and $1.5-2 \%$ for maintenance), $\mathrm{N}_{2} \mathrm{O}(66 \%)$ and $\mathrm{O}_{2}(34 \%)$. Seven animals were pressure injected, using a $1 \mu \mathrm{l}$ Hamilton syringe, with $0.3 \mu \mathrm{l}$ of a $1.5 \%$ CTb solution (List Biological Laboratories, Campbell, CA, USA), in the left VLMlat, according to the stereotaxic coordinates of Paxinos and Watson (1998). Two rats were iontophoretically injected in the same region with $1 \%$ of a low-salt CTb solution (List Biological Laboratories), using 25-30 $\mu \mathrm{m}$ glass micropipettes and a $2 \mu \mathrm{A}$ continuous current, over $10 \mathrm{~min}$. The remaining five animals were used for control injections, in areas surrounding the VLMlat. For this purpose the rats were pressure injected in the $\mathrm{Sp}_{5} \mathrm{C}(n=3 ; 0.5 \mu \mathrm{l})$ and LRt $(n=2 ; 0.4 \mu \mathrm{l})$ with a CTb solution prepared as above.

After completion of the injections, Hamilton syringes or micropipettes were left in situ for 10-15 min, before being slowly retracted. Five days later, the animals were reanaesthetized with chloral hydrate $(0.35 \mathrm{~g} / \mathrm{kg}$ body weight) and perfused through the ascending aorta with $1000 \mathrm{ml}$ of $4 \%$ paraformaldehyde in $0.1 \mathrm{M}$ phosphate buffer (PB), pH 7.4. The brains and part of spinal segment $\mathrm{C}_{1}$ were removed, immersed in fixative for $4 \mathrm{~h}$ and in $30 \%$ sucrose in $\mathrm{PB}$, for 2 days at $4{ }^{\circ} \mathrm{C}$. Before sectioning, the caudal part of the brains was trimmed at the level of the pyramidal decussation (about $0.8 \mathrm{~mm}$ caudal to the obex; Kalia and Fuxe, 1985).

Coronal sections were cut in a freezing microtome at $40 \mu \mathrm{m}$ and serially collected in $0.1 \mathrm{M}$ phosphate-buffered saline (PBS) and two adjacent sections in every three were immunostained for CTB. Sections were washed in PBS containing $0.5 \%$ Triton X-100 (PBST) and incubated for $2-4$ days, at $4{ }^{\circ} \mathrm{C}$, in an anti-CTb antibody raised in goat (List Biological Laboratories), diluted at $1: 40,000$ in PBST. After repeated washings, the sections were incubated in a biotinylated horse anti-goat antiserum followed by an avidin-biotin complex reagent (ABC; Vector Laboratories (UK), Burlingame, CA, USA, both for $1 \mathrm{~h}$, at 1:200. After a 10-min washing in $0.05 \mathrm{M}$ Tris-buffered saline, $\mathrm{pH} 7.6$, sections were incubated for $10-15 \mathrm{~min}$ with $0.1 \% 3,3$-diaminobenzidine tetrahydrochloride (DAB) and $0.012 \% \mathrm{H}_{2} \mathrm{O}_{2}$, diluted in the same buffer.

Abbreviations used in the figures

3

7

10

12

$3 \mathrm{~V}$

4V

A

$\mathrm{A}_{5}$

ac

Acb

AP

APT

$\mathrm{Aq}$

cc

$\mathrm{Cu}$

DEn

DLPAG

DpMe

DR

EW

f

ic

icp

LPB

LPO

LRtm oculomotor nucleus

facial nucleus

dorsal motor nucleus of vagus

hypoglossal nucleus

$3^{\text {rd }}$ ventricle

$4^{\text {th }}$ ventricle

ambiguus nucleus

$\mathrm{A}_{5}$ noradrenergic cell group

anterior commissure

nucleus accumbens

area postrema

anterior pretectal nucleus

aqueduct Sylvius

central canal

cuneate nucleus

dorsal endopiriform nucleus

dorsolateral periaqueductal gray

deep mesencephalic nucleus

dorsal raphe nucleus

Edinger-Westphal nucleus

fornix

internal capsule

inferior cerebellar peduncle

lateral parabrachial nucleus

lateral preoptic area

lateral reticular nucleus, magnocellular part

\begin{tabular}{|c|c|}
\hline $\begin{array}{l}\text { LRtp } \\
\text { ml }\end{array}$ & $\begin{array}{l}\text { lateral reticular nucleus, parvicellular part } \\
\text { medial lemniscus }\end{array}$ \\
\hline MPA & medial preoptic area \\
\hline MPB & medial parabrachial nucleus \\
\hline opt & optic tract \\
\hline $\mathrm{PeF}$ & perifornical nucleus \\
\hline PFI & paraflocculus \\
\hline $\mathrm{PH}$ & posterior hypothalamic area \\
\hline PR & prerubral field \\
\hline Py & pyramidal tract \\
\hline Pyx & pyramidal decussation \\
\hline $\mathrm{RCh}$ & retrochiasmatic area \\
\hline $\operatorname{scp}$ & superior cerebellar peduncle \\
\hline SI & substantia innominata \\
\hline SNR & substantia nigra, reticular part \\
\hline $\mathrm{Sp}_{5} \mathrm{O}$ & spinal trigeminal nucleus, pars oralis \\
\hline SubC & subcoeruleus nucleus \\
\hline TC & tuber cinereum area \\
\hline VA & ventral anterior thalamic nucleus \\
\hline $\mathrm{Ve}$ & vestibular nucleus \\
\hline VL & ventrolateral thalamic nucleus \\
\hline VP & ventral pallidum \\
\hline VPL & ventral posterolateral thalamic nucleus \\
\hline VTRZ & visual tegmental relay zone \\
\hline ZI & zona incerta \\
\hline
\end{tabular}



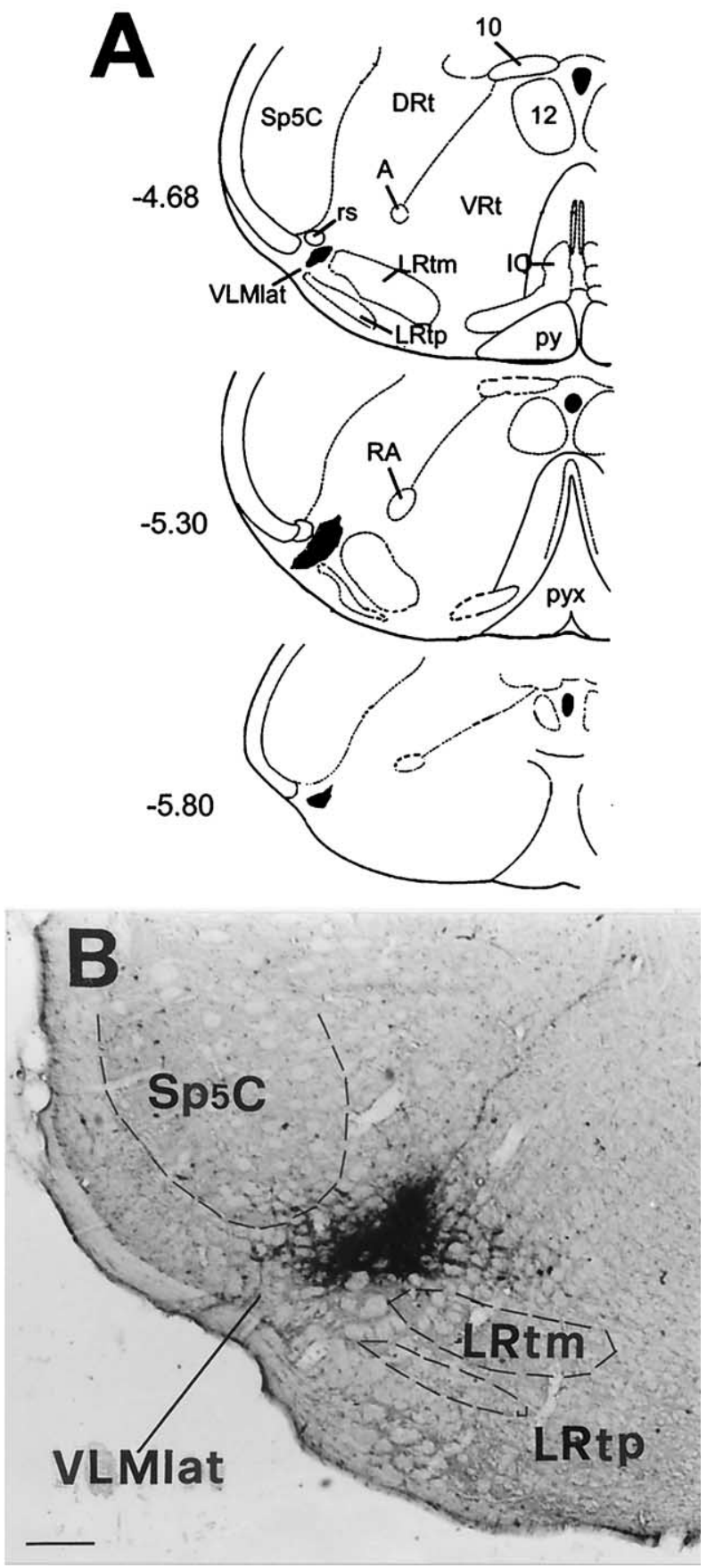

Fig. 1. CTb injection sites in the VLMlat. In A, diagrams depicting the injection site in animal 2356, in three medullary sections obtained at the rostrocaudal level indicated by the distance (in $\mathrm{mm}$ ) from the interaural line. The injection sites include the central core (black) and the peripheral halo (gray). In B, photomicrograph of an injection site in the VLMlat at the level $-4.68 \mathrm{~mm}$, in animal 1346. Scale bar $=0.16 \mathrm{~mm}$.

After washing in PBS, the first set of sections of the two adjacent sections out of three taken from the section series was mounted on gelatin-coated slides, cleared in xylene and coverslipped with Eukitt. In order to delimitate brain nuclei, the additional set of sections was counterstained with formol-Thionin (Donovick, 1974) and camera lucida drawings were performed according to Paxinos and Watson (1998). Retrogradely labeled neurons that occurred in five sections randomly taken from the rostrocaudal levels indicated in Fig. 2C, were plotted in the respective drawings. For quantitative analysis, all the retrogradely labeled neurons occurring in the brain nuclei identified in Thionin-stained sections were counted. The seven animals with pressure injections in the VLMlat were considered for quantitative analysis by counting the retrogradely labeled neurons plotted in camera lucida drawings.

\section{Anterograde tracing experiments}

Eleven rats were anesthetized as above and iontophoretically injected with a 10\% BDA solution (mol. wt: $10 \mathrm{kDa}$; Molecular Probes Inc., Leiden, The Netherlands) in $0.1 \mathrm{M} \mathrm{PB}, \mathrm{pH} 7.2$, through 25-30 $\mu \mathrm{m}$-diameter-tip glass micropipettes using a positive $2.5 \mu \mathrm{A} \mathrm{DC}$ current for $20-30 \mathrm{~min}$. The left part of the lateral hypothalamic area $(\mathrm{LH} ; n=3)$, paraventricular nucleus $(\mathrm{Pa} ; n=2)$, red nucleus (R; $n=2)$, ventrolateral periaqueductal gray (VLPAG; $n=2$ ) and lateral nucleus of the cerebellum (Lat; $n=2$ ), were injected following the stereotaxic coordinates of Paxinos and Watson (1998).

The rats were reanesthetized and perfused as described in the retrograde tracing experiments. Serial $50 \mu \mathrm{m}$-thick frozen sections passing through the injection sites and from the caudal medulla oblongata were incubated for $1 \mathrm{~h}$ with $A B C$, as above. Bound peroxidase was revealed using $D A B$ as above and, after repeated washing with PBS, one set of reacted sections was mounted on gelatin-coated slides while the other set was counterstained with formol-Thionin (Donovick, 1974).

The distribution of anterogradely labeled fibers at the CVLM was established using a procedure similar to that described for $\mathrm{CTb}$, but no quantification was performed. Five well-stained sections taken from two rostrocaudal levels of the medulla oblongata ( 4.8 and $5.8 \mathrm{~mm}$ caudal to the interaural line) were used to obtain camera lucida drawings depicting anterogradely labeled fibers. The distinct CVLM subareas were identified according to previous cytoarchitectonic studies (Kalia and Fuxe, 1985; Kapogianis et al., 1982; Paxinos and Watson, 1998).

\section{RESULTS}

\section{Injection sites}

$\mathrm{CTb}$ injection sites consisted of a homogeneous, compact core surrounded by a halo in which dark areas intermingled with lighter zones (Fig. 1). A few retrogradely labeled cells were observed around the peripheral halo probably due to uptake from the more central areas. In accordance with previous studies (Ericson and Blomqvist 1988; Lima et al., 1991), only the central core and the peripheral halo were included in the injection sites. In the animals considered for quantitative analysis of retrograde labeling, the injection sites were restricted to the VLMlat, between the levels of the area postrema and pyramidal decussation (Fig. 1A). Control injections in the $\mathrm{Sp}_{5} \mathrm{C}$ were located in the ventral third of the nucleus while injections in the LRt encompassed mainly its magnocellular component.

BDA injection sites presented a granular core of densely packed perikarya surrounded by a narrow rim formed by scarcely labeled neurons (Fig. 2). More peripherally there was a region of densely labeled fibers, probably indicating uptake from the more central areas. Only the central region and the rim were included in the 

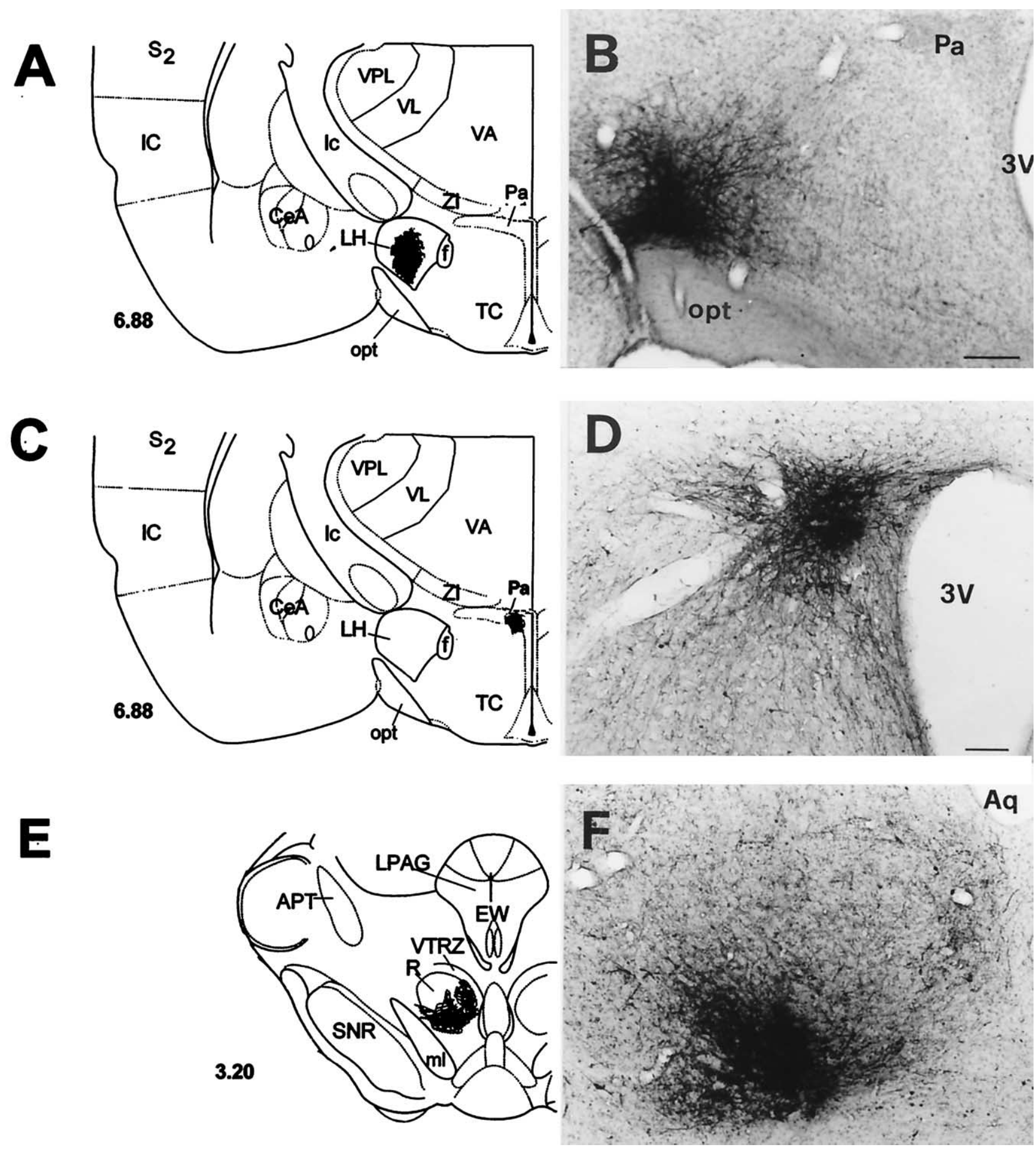

Fig. 2. Diagrams and photomicrographs of $B D A$ injection sites in the $L H(A, B), P a(C, D), R(E, F), V L P A G(G, H)$ and Lat (I, J). Panels $B$ and $H$ and figures $\mathrm{D}, \mathrm{F}$ and $\mathrm{J}$ are at the same magnification. Scale bars $=0.25 \mathrm{~mm}$.

injection site (Veenmam et al., 1992; Wouterlood and Jorritsma-Byham, 1993). BDA injection sites in the LH were centered in the median half of the nucleus (Fig. $2 \mathrm{~A}$, $\mathrm{B})$. Injections in the $\mathrm{Pa}$ encompassed mainly the medial parvocellular component of the nucleus (Fig. 2C, D), reaching occasionally the lateral magnocellular part. In- jections in the $\mathrm{R}$ encompassed both the magno- and parvocellular parts of the nucleus (Fig. 2E, F). Injections in the VLPAG were located on its median portion (Fig. $2 \mathrm{G}, \mathrm{H})$. Cerebellar injections were located in the Lat extending ventrally to reach the borders of the inferior cerebellar peduncle (icp; Fig. 2I, J). 

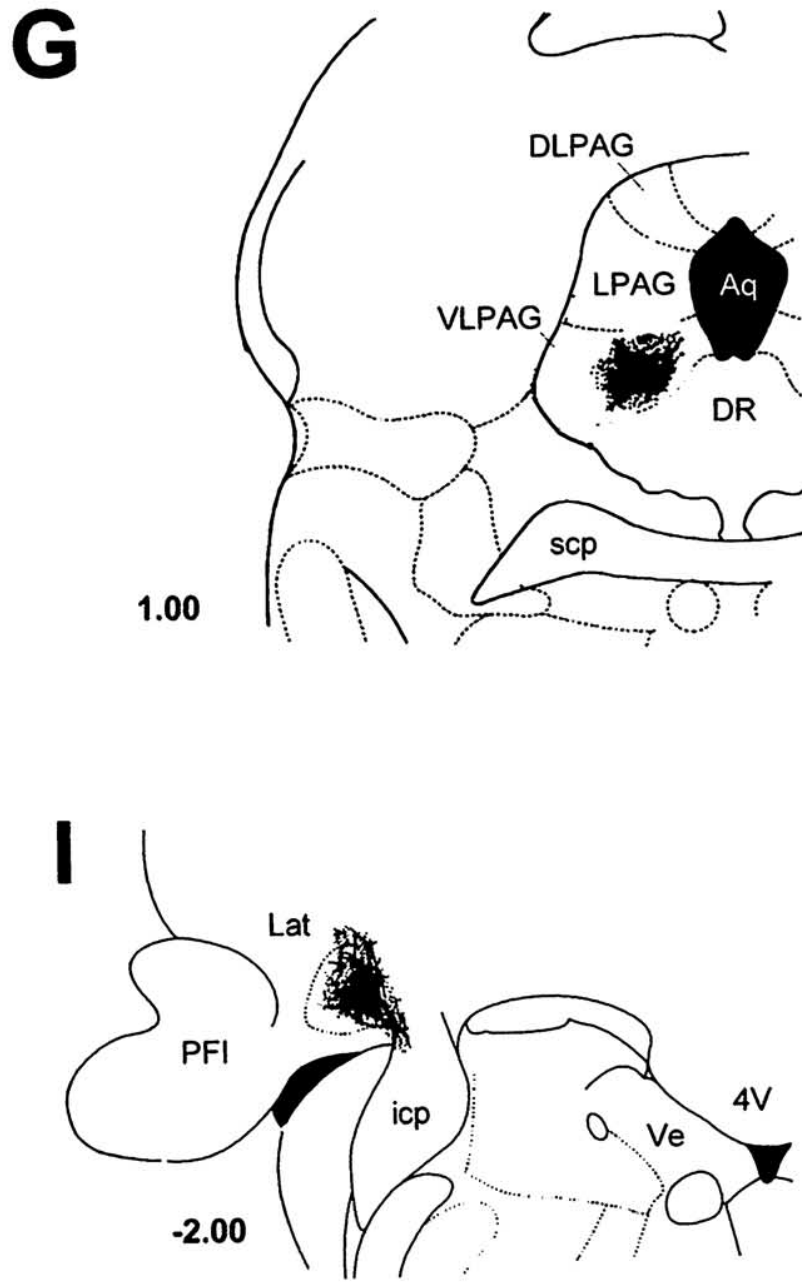
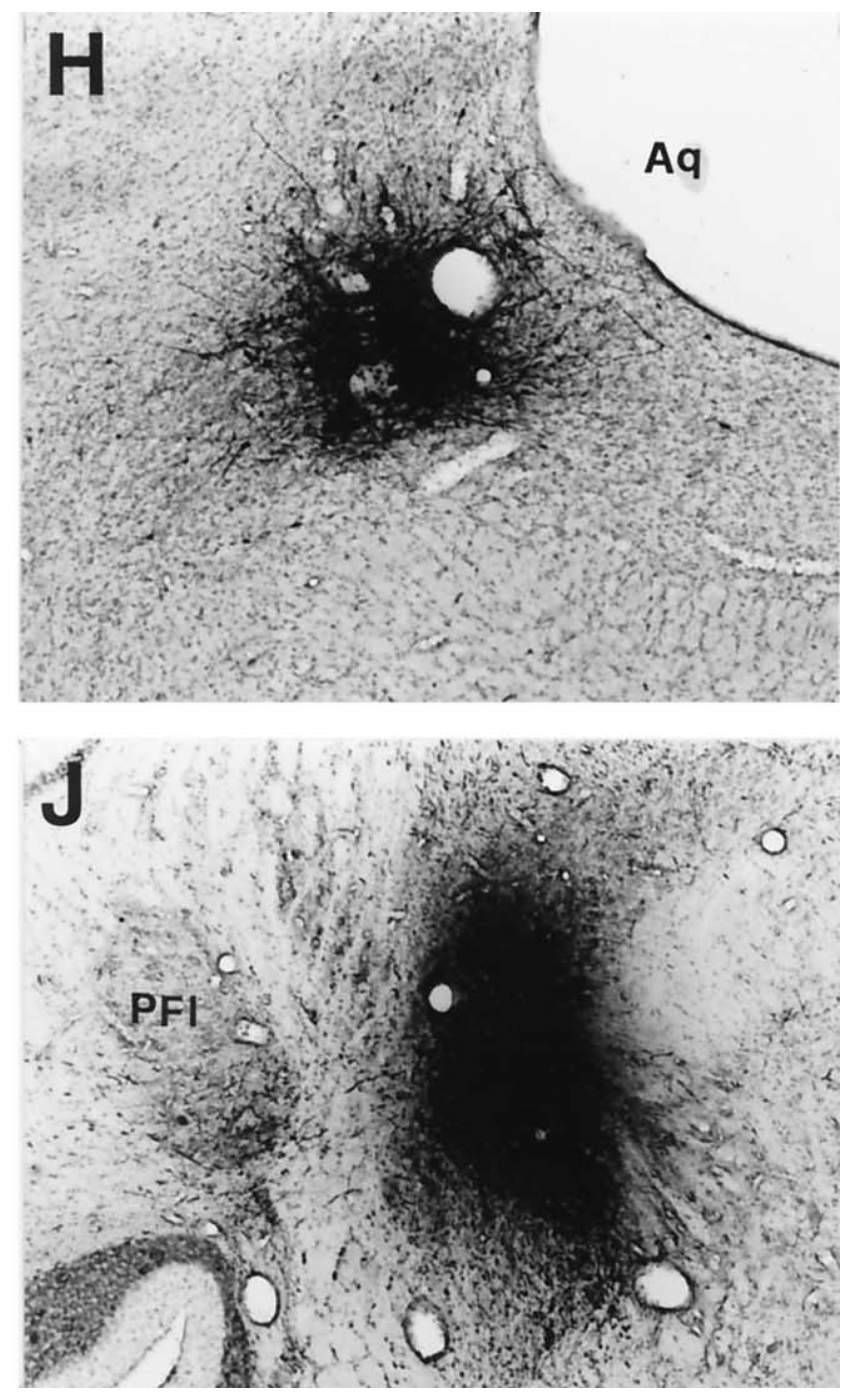

Fig. 2. (G-J).

\section{Retrograde labeling with CTb}

Injections in the VLMlat. After injections in the VLMlat, retrogradely labeled neurons were observed in several areas along the rostrocaudal extension of the brain (Figs. 3 and 4; Table 1). Similar patterns of retrograde labeling were observed after pressure and iontophoretic deliveries, but counting was only performed in the former injection type (Table 1).

\section{Forebrain}

At cortical regions, retrogradely labeled neurons largely prevailed at the primary and secondary somatosensory cortex, with a contralateral predominance (Figs. 3B-D and $4 A)$. Retrogradely labeled neurons also occurred in the insular cortex (IC) and, more moderately, in the primary and secondary motor cortex $\left(\mathrm{M}_{1}\right.$ and $\left.\mathrm{M}_{2}\right)$, mainly contralaterally (Fig. 3A-D). In four animals (1377, 2262, 2263 and 2356), some CTb labeled neurons occurred bilaterally at the prelimbic (PRL)/infralimbic (IL) cortex (Fig. 3A, B). Other forebrain regions with retrogradely labeled neurons included the central amygdaloid nucleus (CeA; Figs. 3D and $4 \mathrm{~B}$ ), bed nucleus of the stria terminalis (BST; Fig. $3 \mathrm{C}$ ) and dorsal endopiriform nucleus (Fig. 3B), with an ipsilateral prevalence.

\section{Diencephalon}

At the diencephalon, the most prominent projection was originated from the hypothalamus, mainly at the $\mathrm{LH}$ and $\mathrm{Pa}$, with an ipsilateral prevalence (Figs. 3D, 4C). Lower numbers of labeled neurons were observed at the posterior hypothalamus, preoptic region of the hypothalamus, tuber cinereum area, perifornical region, zona incerta and retrochiasmatic area, mainly ipsilaterally (Fig. 3C). In some animals scarce retrograde labeling was observed in the region of the ventral pallidum and substantia innominata and in the nucleus accumbens, mainly ipsilaterally (Fig. 3C). 


\section{Mesencephalon}

At the mesencephalic level, the most prominent projection was originated from the periaqueductal gray (PAG), mainly from the VLPAG, bilaterally (Figs. 3E, 4D). In some animals, retrogradely labeled cells were observed at the region of the Edinger-Westphal and dorsal raphe nuclei in the $\mathrm{R}$ and oculomotor nucleus (3), with a contralateral prevalence, and bilaterally in the deep mesencephalic nucleus (Figs. 3E, 4D).

\section{Pons and cerebellum}

The parabrachial complex was the major source of pontine projections to the VLMlat. High numbers of neurons were observed at the lateral parabrachial nucleus, mainly ipsilaterally (Figs. 3F, 4E). Some retrogradely labeled neurons were observed at the medial parabrachial and KöllikerFuse (KF) nuclei, mainly ipsilaterally (Fig. 3F). The region of the $A_{5}$ noradrenergic cell group also presented intense bilateral retrograde labeling (Fig. 3F). Some neurons occurred bilaterally in the coerulear region namely in the locus coeruleus (LC) and nucleus subcoeruleus (Fig. 3F and $4 \mathrm{E}$ ). More moderate bilateral labeling was observed in the region of the superior olive (SO; Fig. 3F).

In four animals (1378, 1408, 2262 and 2263) retrogradely labeled neurons occurred at the cerebellum, namely in the Lat, with an ipsilateral prevalence (Fig. 3G).

\section{Medulla oblongata}

At the medulla oblongata, very intense retrograde labeling was observed at the superficial layers of the $\mathrm{Sp}_{5}$ mainly ipsilaterally, and at the nucleus tractus solitarii (Sol; Figs. $3 \mathrm{H}, \mathrm{I}, 4 \mathrm{~F})$. Moderate retrograde labeling was observed at the nucleus raphe magnus (RMg; Fig. $3 F, G$ ), with an ipsilateral prevalence. The dorsal (DRt) and ventral (VRt) reticular nuclei contained numerous retrogradely labeled neurons, bilaterally (Figs. 3H, I, 4F). Bilateral labeling was observed at the RVLM and at the magnocellular part of the LRt (Fig. 3H, I). A considerable amount of retrogradely labeled neurons occurred at the contralateral VLMlat (Fig. $3 \mathrm{H}, \mathrm{I})$. A few neurons were observed at the area postrema and, contralaterally, at the inferior olive (IO).

\section{Control injections}

Following injections in the $\mathrm{Sp}_{5} \mathrm{C}$, retrogradely labeled neurons in the forebrain occurred at the somatosensory cortex, contralaterally, and CeA, bilaterally. In the diencephalon, the most important projections occurred from the thalamus namely from the parafascicular thalamic nucleus and ventromedial thalamic nucleus, both bilaterally. Labeled brainstem regions included the PAG, namely its dorsolateral part and the parabrachial complex, both bilaterally, and all the rostrocaudal components of the trigeminal complex, mainly ipsilaterally.

After injections in the LRt, retrogradely labeled neurons occurred at the $M_{1} / M_{2}$ regions and PRL/IL area. A very intense labeling was observed at the globus pallidus, substantia nigra, R and Lat, SO, DRt, Sol and IO.
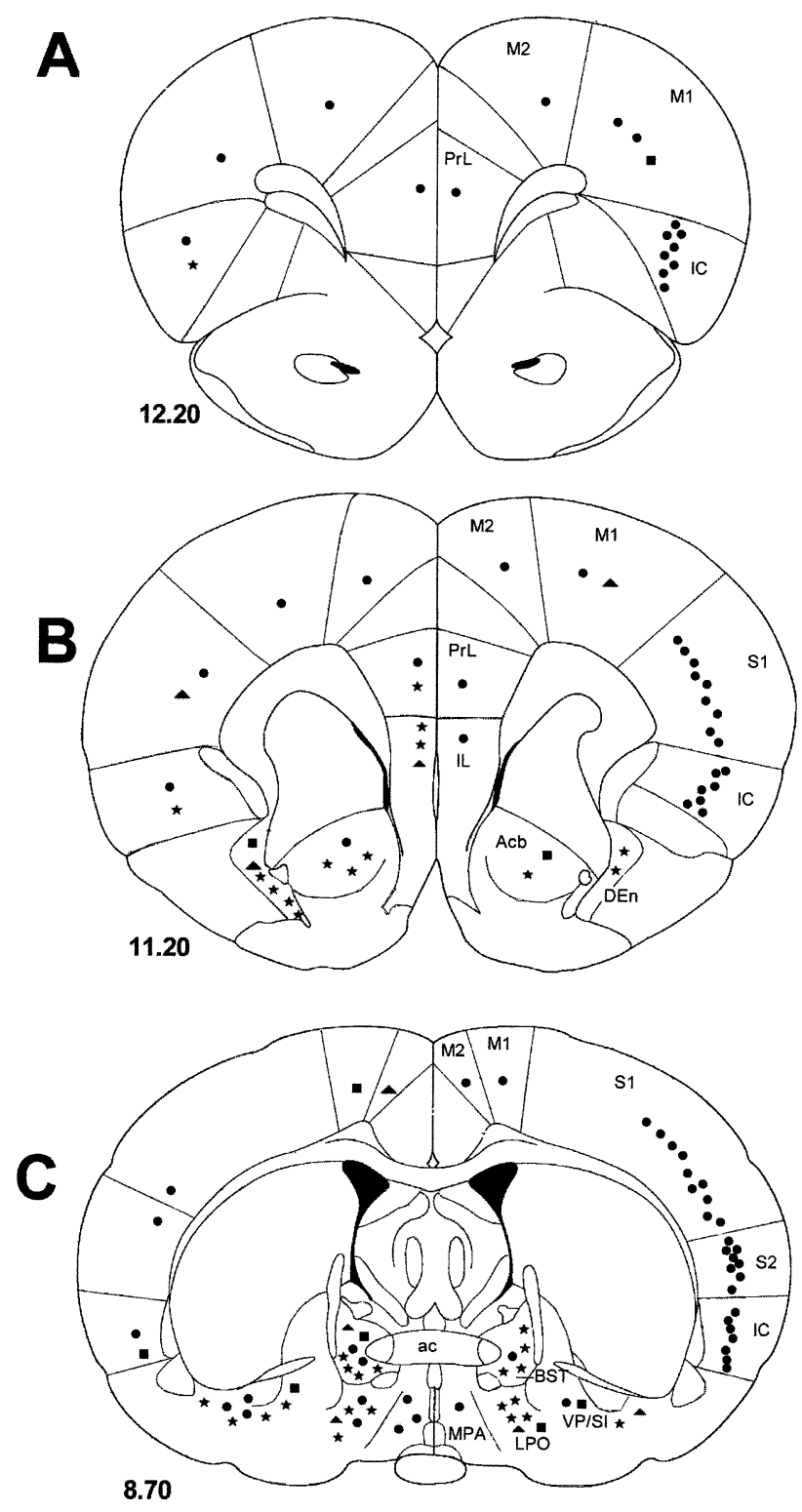

Fig. 3. Diagrams illustrating the distribution of retrogradely labeled neurons in the brain after CTb injections in the VLMlat (in animal 2262). Each drawing was taken from representative rostrocaudal levels, indicated by the distance (in $\mathrm{mm}$ ) from the interaural line. Symbols represent $20(\mathbf{O}), 10(\mathbf{\square})$, five $(\boldsymbol{\Delta})$ or one $\left(^{*}\right)$ neuron. Left side is ipsilateral to the injection site.

\section{Anterograde labeling with BDA}

Following injections in the $\mathrm{LH}$, strong anterograde labeling was observed bilaterally in the VLMlat (Fig. 5A, B) extending dorsomedially to the region of the ipsilateral $A_{1}$ noradrenergic cell group (Fig. 5A). Injections in the $\mathrm{Pa}$ produced intense labeling of the VLMlat, mainly ipsilaterally (Fig. 5C), which reached occasionally the $A_{1}$ region. Injections in the $R$ produced contralateral labeling mainly in the lateral LRt and VLMlat (Fig. 5D). After VLPAG injections, labeled fibers occupied mainly the 

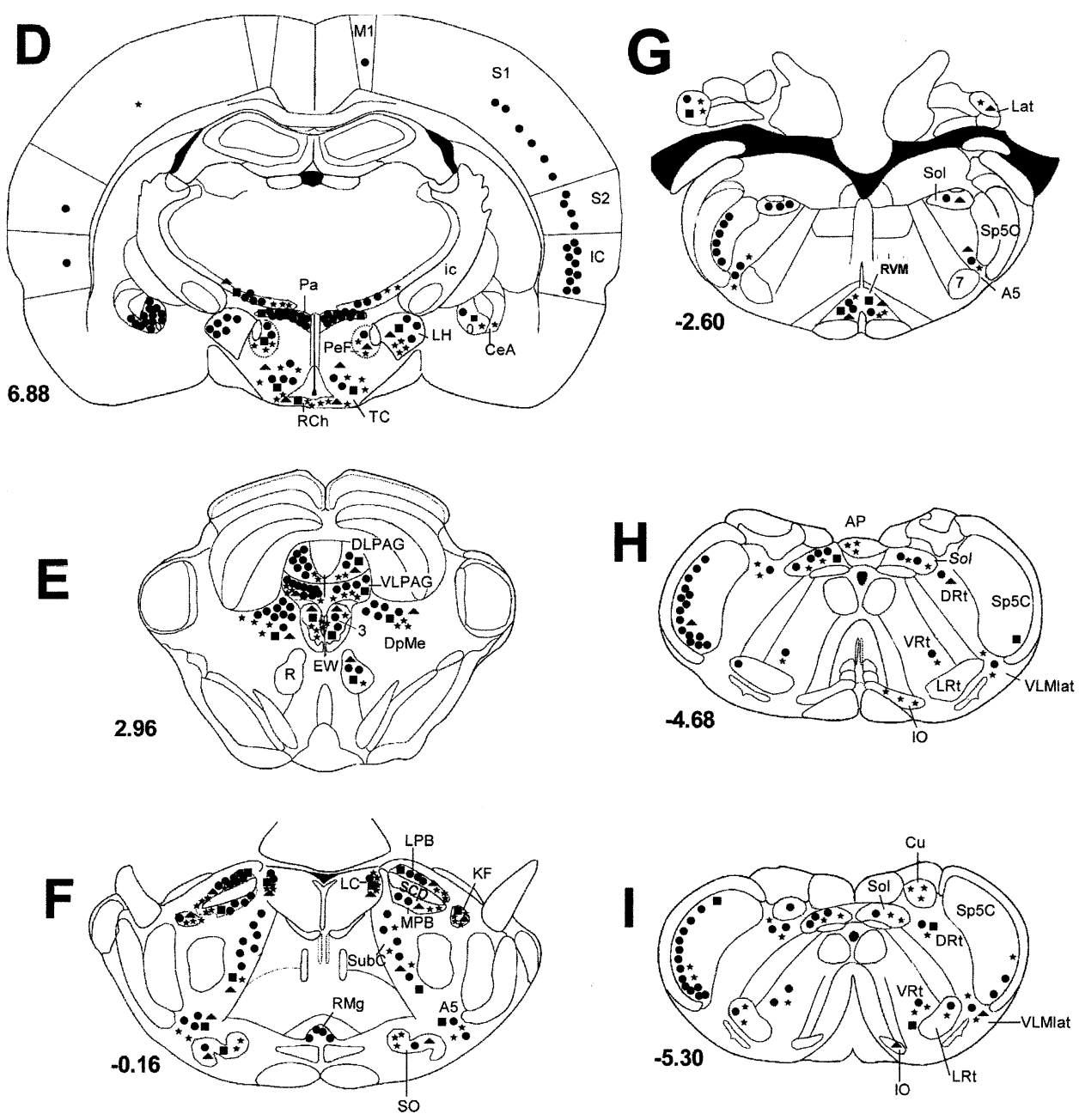

Fig. 3. (D-I).

VLMlat, bilaterally (Fig. 5E). A few occurred at the lateral LRt, with a slight ipsilateral prevalence. Cerebellar injections in the Lat resulted in anterograde labeling in the LRt and VLMlat, mainly ipsilaterally and, occasionally, in the $A_{1}$ region (Fig. $5 F$ ).

\section{DISCUSSION}

\section{Technical considerations}

The present study establishes the brain afferents to the VLMlat by the use of retrograde and anterograde tracing with, respectively, CTb and BDA. CTb was chosen because it produces intense retrograde labeling from relatively small injection sites (Ericson and Blomqvist, 1988; Lima and Coimbra, 1991; Lima et al., 1991; Tavares and Lima, 1994), which were here confined to the VLMlat. The small size of the CTb injection sites probably accounted to some inter-animal variability, namely in what concerns the lack of labeling of brain nuclei detected in some animals. Similar inter-animal variation was detected after small CTb injections in other CNS regions and was ascribed to unequal filling of territories in such injection sites (Ericson and Blomqvist, 1988; Lima et al., 1991; Tavares and Lima, 1994). Retrograde labeling after injections in the VLMlat was probably produced exclusively by transport from that region since the pattern of labeling was different from those obtained after control injections in the surrounding regions. Along with negative outcomes of neuronal labeling due to $\mathrm{CTb}$ uptake by passing fibers (Lima et al., 1991; Tavares and Lima, 1994), some positive findings were reported (Luppi et al., 1990). It is, however, unlikely that fibers coursing in the VLMlat accounted for the neuronal labeling since these axons belong mainly to spinofugal pathways (Snyder et al., 1978; Yamada and Otani, 1978; Yamada et al., 1991). As to the rubrospinal tract, which courses laterally to the VLMlat (cf. Fig. 1A and Paxinos and Watson, 1998), it was probably not encompassed by the bulk of the injection sites. In agreement, rubral labeling was also demonstrated after CTb iontophoresis in the VLMlat, an injection procedure that prevents uptake by passing fibers (Luppi et al., 1990) and anterograde labeling was observed in the VLMlat after BDA injections in the R. These BDA tracing experiments, 

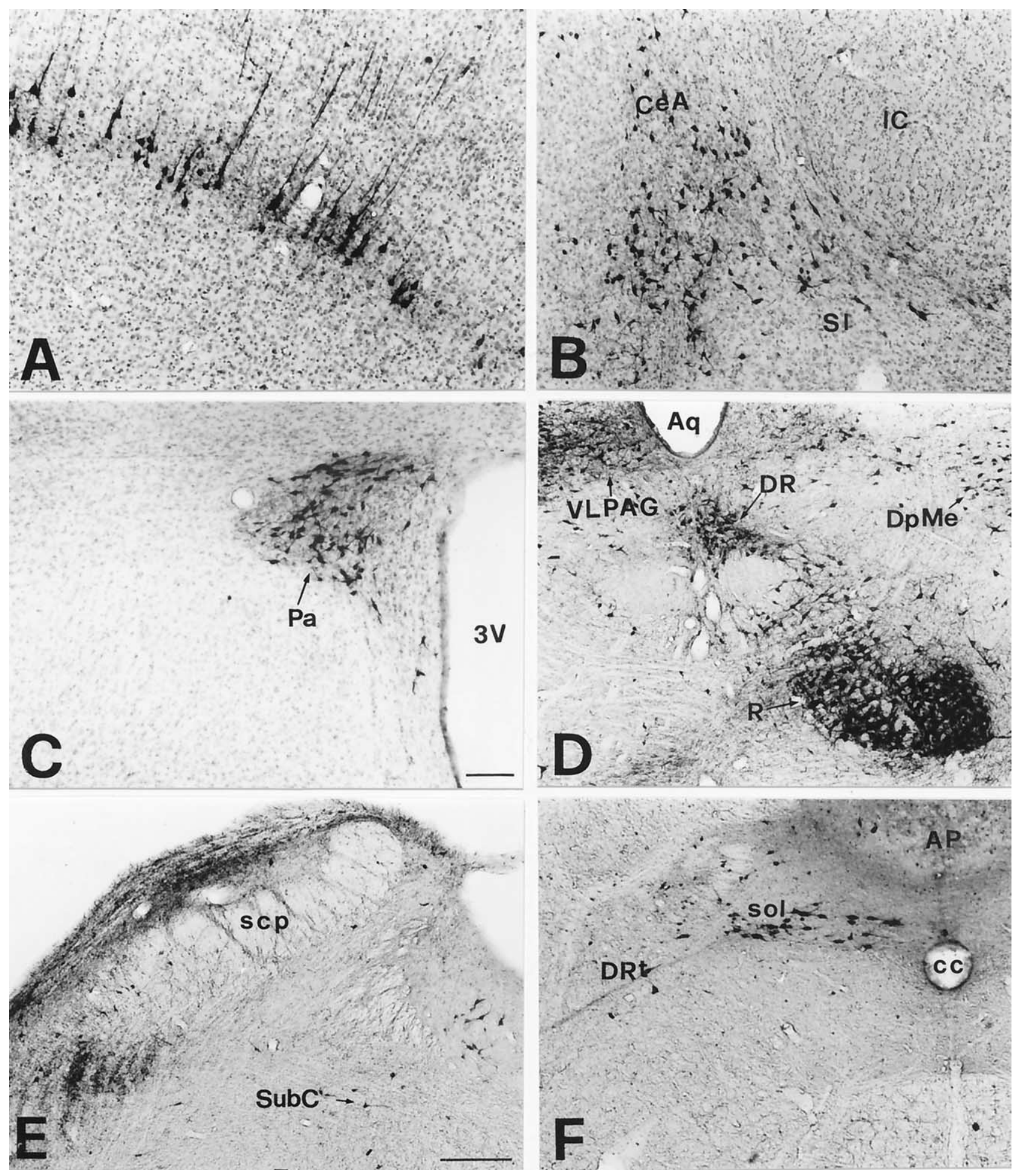

Fig. 4. Photomicrographs depicting retrogradely labeled cells in the secondary somatosensory cortex (A), CeA/SI (B), Pa (C), R, DR and VLPAG (D), $P B N$ region $(E)$ and dorsal medulla oblongata $(F)$ following $C T b$ injections in the VLMlat. Panels $A$ and $D$ are contralateral to the injection site. Scale bars $=150 \mu \mathrm{m}$. Panels $A-D$ and $F$ are at the same magnification.

performed with the main purpose of clarifying the precise area of termination of some VLMlat afferent fibers were, therefore, a valuable complement of the retrograde tracing studies. The nuclei injected with BDA presented intense retrograde labeling and were further selected based on their well-established involvement in the control of autonomic parameters (LH and $\mathrm{Pa}$ ), nociception (PAG) and motor reactions ( $\mathrm{R}$ and Lat; Paxinos, 1995). 
Table 1. Numbers of neurons retrogradely labeled in the ipsilateral (ipsi) and contralateral (cont) forebrain (Foreb.), diencephalon (Dience.), mesencephalon (Mesence.), pons, cerebellum (Cereb.) and medulla oblongata (Med. obl.) after CTb injections in the VLMlat

\begin{tabular}{|c|c|c|c|c|c|c|c|c|c|c|c|c|c|c|}
\hline & \multicolumn{2}{|l|}{1346} & \multicolumn{2}{|c|}{1377} & \multicolumn{2}{|c|}{1378} & \multicolumn{2}{|l|}{1408} & \multicolumn{2}{|c|}{2262} & \multicolumn{2}{|c|}{2263} & \multicolumn{2}{|c|}{2356} \\
\hline & ipsi & cont & ipsi & cont & ipsi & cont & ipsi & cont & ipsi & cont & ipsi & cont & ipsi & cont \\
\hline \multicolumn{15}{|l|}{ Foreb. } \\
\hline$M_{1} / M_{2}$ & 46 & 48 & 48 & 97 & 3 & 24 & 36 & 96 & 95 & 175 & 256 & 484 & 0 & 0 \\
\hline $\mathrm{S}_{1} / \mathrm{S}_{2}$ & 76 & 659 & 65 & 910 & 54 & 160 & 32 & 780 & 85 & 740 & 232 & 1340 & 0 & 0 \\
\hline $\mathrm{IC}$ & 78 & 191 & 51 & 413 & 15 & 169 & 91 & 600 & 92 & 640 & 150 & 695 & 64 & 189 \\
\hline PrL/IL & 0 & 0 & 2 & 5 & 0 & 0 & 0 & 0 & 48 & 60 & 185 & 207 & 12 & 34 \\
\hline $\mathrm{DEn}$ & 2 & 0 & 2 & 1 & 2 & 1 & 8 & 1 & 19 & 2 & 54 & 6 & 7 & 2 \\
\hline $\mathrm{CeA}$ & 0 & 0 & 2 & 2 & 32 & 0 & 126 & 5 & 260 & 32 & 248 & 16 & 0 & 0 \\
\hline BST & 0 & 0 & 18 & 6 & 12 & 0 & 12 & 0 & 59 & 24 & 107 & 12 & 14 & 6 \\
\hline \multicolumn{15}{|l|}{ Dience. } \\
\hline VP/SI & 0 & 0 & 51 & 22 & 0 & 0 & 0 & 8 & 74 & 36 & 65 & 21 & 0 & 0 \\
\hline$A c B$ & 0 & 0 & 9 & 2 & 7 & 1 & 0 & 0 & 23 & 11 & 17 & 8 & 0 & 0 \\
\hline MPA & 0 & 0 & 8 & 2 & 1 & 0 & 8 & 2 & 60 & 20 & 62 & 21 & 0 & 0 \\
\hline LPO & 0 & 0 & 12 & 4 & 2 & 0 & 12 & 0 & 48 & 19 & 52 & 18 & 0 & 0 \\
\hline $\mathrm{TC}$ & 15 & 19 & 26 & 7 & 15 & 3 & 21 & 17 & 98 & 58 & 116 & 44 & 2 & 6 \\
\hline $\mathrm{RCh}$ & 3 & 2 & 5 & 2 & 2 & 0 & 24 & 2 & 19 & 8 & 14 & 8 & 3 & 2 \\
\hline $\mathrm{Pa}$ & 58 & 37 & 90 & 29 & 67 & 12 & 112 & 61 & 250 & 190 & 280 & 182 & 99 & 38 \\
\hline LH & 325 & 78 & 74 & 24 & 40 & 21 & 150 & 67 & 120 & 79 & 159 & 92 & 110 & 82 \\
\hline $\mathrm{ZI}$ & 78 & 32 & 56 & 11 & 12 & 10 & 59 & 35 & 98 & 72 & 31 & 23 & 45 & 26 \\
\hline $\mathrm{PeF}$ & 26 & 36 & 4 & 2 & 4 & 4 & 15 & 10 & 58 & 27 & 71 & 23 & 36 & 15 \\
\hline $\mathrm{PH}$ & 56 & 25 & 4 & 2 & 6 & 2 & 9 & 6 & 58 & 16 & 49 & 28 & 11 & 5 \\
\hline \multicolumn{15}{|l|}{ Mesence. } \\
\hline DLPAG & 10 & 2 & 20 & 8 & 5 & 2 & 29 & 8 & 142 & 57 & 92 & 36 & 4 & 2 \\
\hline VLPAG & 11 & 21 & 85 & 52 & 43 & 6 & 84 & 24 & 189 & 94 & 210 & 96 & 24 & 13 \\
\hline DpMe & 0 & 0 & 54 & 28 & 19 & 13 & 68 & 45 & 197 & 118 & 183 & 109 & 5 & 3 \\
\hline $\mathrm{R}$ & 0 & 0 & 0 & 190 & 0 & 31 & 0 & 55 & 0 & 56 & 0 & 175 & 0 & 52 \\
\hline 3 & 0 & 0 & 9 & 29 & 13 & 18 & 3 & 22 & 18 & 56 & 19 & 68 & 35 & 76 \\
\hline $\begin{array}{l}\text { EW/ } \\
\text { DR }\end{array}$ & 0 & 0 & 3 & 1 & 2 & 1 & 5 & 2 & 2 & 6 & 5 & 6 & 4 & 3 \\
\hline VTRZ & 0 & 1 & 0 & 32 & 1 & 7 & 1 & 7 & 18 & 27 & 12 & 24 & 0 & 0 \\
\hline \multicolumn{15}{|l|}{ Pons } \\
\hline LPB & 23 & 5 & 57 & 28 & 29 & 6 & 98 & 27 & 159 & 78 & 144 & 60 & 0 & 0 \\
\hline MPB & 5 & 3 & 6 & 4 & 3 & 3 & 20 & 7 & 92 & 47 & 98 & 52 & 0 & 0 \\
\hline $\mathrm{KF}$ & 14 & 2 & 43 & 8 & 17 & 4 & 18 & 11 & 28 & 19 & 56 & 40 & 0 & 0 \\
\hline $\mathrm{A}_{5}$ & 32 & 8 & 51 & 12 & 48 & 9 & 72 & 52 & 119 & 78 & 105 & 58 & 24 & 16 \\
\hline LC & 2 & 1 & 14 & 8 & 9 & 5 & 16 & 15 & 58 & 39 & 32 & 28 & 28 & 22 \\
\hline so & 0 & 0 & 0 & 0 & 0 & 0 & 0 & 0 & 37 & 28 & 32 & 35 & 58 & 36 \\
\hline SubC & 11 & 4 & 47 & 15 & 15 & 5 & 28 & 26 & 156 & 118 & 22 & 63 & 10 & 6 \\
\hline \multicolumn{15}{|l|}{ Cereb. } \\
\hline Lat & 0 & 0 & 0 & 0 & 10 & 3 & 18 & 9 & 32 & 6 & 27 & 5 & 0 & 0 \\
\hline \multicolumn{15}{|l|}{ Med. obl. } \\
\hline AP & 0 & 0 & 2 & 0 & 2 & 0 & 2 & 0 & 3 & 0 & 5 & 0 & 6 & 0 \\
\hline Sol & 0 & 0 & 125 & 46 & 112 & 22 & 196 & 82 & 214 & 89 & 237 & 96 & 420 & 38 \\
\hline $\mathrm{Sp}_{5} \mathrm{C}$ & 0 & 0 & 698 & 26 & 344 & 18 & 654 & 47 & 697 & 76 & 897 & 94 & 765 & 58 \\
\hline DRt & 42 & 38 & 52 & 30 & 35 & 11 & 76 & 38 & 64 & 56 & 65 & 58 & 82 & 44 \\
\hline $\mathrm{Cu}$ & 6 & 0 & 6 & 0 & 5 & 0 & 14 & 0 & 20 & 3 & 23 & 2 & 15 & 3 \\
\hline $\mathrm{RMg}$ & 0 & 0 & 16 & 10 & 17 & 4 & 42 & 14 & 96 & 77 & 93 & 81 & 48 & 12 \\
\hline 10 & 0 & 0 & 0 & 14 & 0 & 0 & 0 & 22 & 0 & 8 & 0 & 14 & 0 & 138 \\
\hline RVLM & 0 & 0 & 0 & 0 & 15 & 11 & 32 & 30 & 63 & 52 & 75 & 61 & 42 & 18 \\
\hline VRt & 0 & 0 & 65 & 34 & 13 & 8 & 62 & 40 & 62 & 54 & 73 & 59 & 58 & 52 \\
\hline LRt & 0 & 0 & 7 & 4 & 0 & 0 & 56 & 51 & 43 & 21 & 51 & 23 & 35 & 12 \\
\hline VLMlat & - & 0 & - & 24 & - & 20 & - & 49 & - & 49 & - & 74 & - & 85 \\
\hline
\end{tabular}

Depending on the rostrocaudal extention of each nucleus, four to eight sections were used to determine the number of retrogradely labelled neurons. For abbreviations see list.

Somatosensory and autonomic afferents

The most prominent projections to the VLMlat were originated from areas related to sensory functions. To the best of our knowledge, projections from the somatosensory cortex to the VLMlat were described for the first time in the present study. The somatosensory and insular cortices were shown to participate in pain control since analgesia is produced upon local instillation of morphine and spinal 

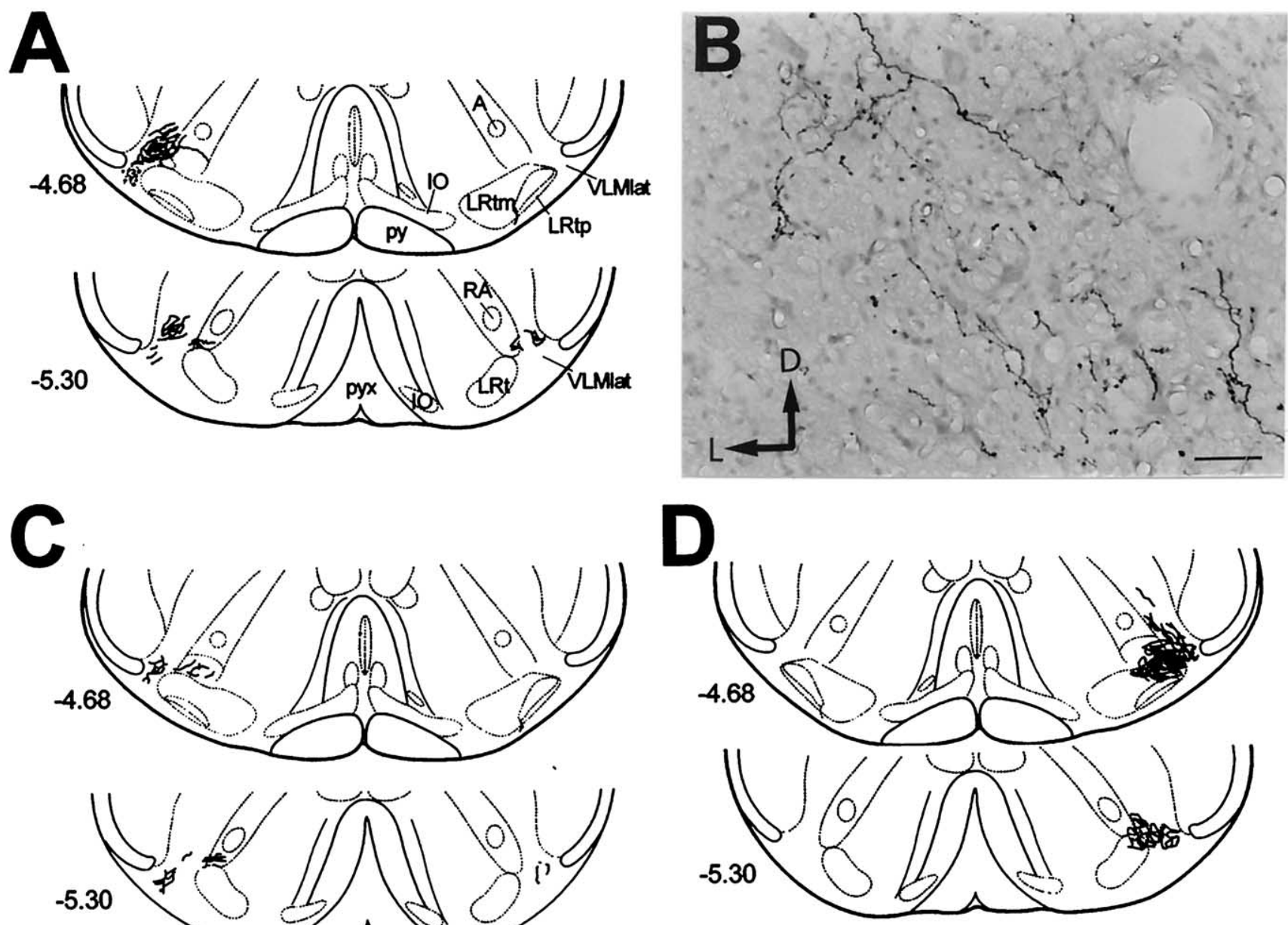

$-5.30$
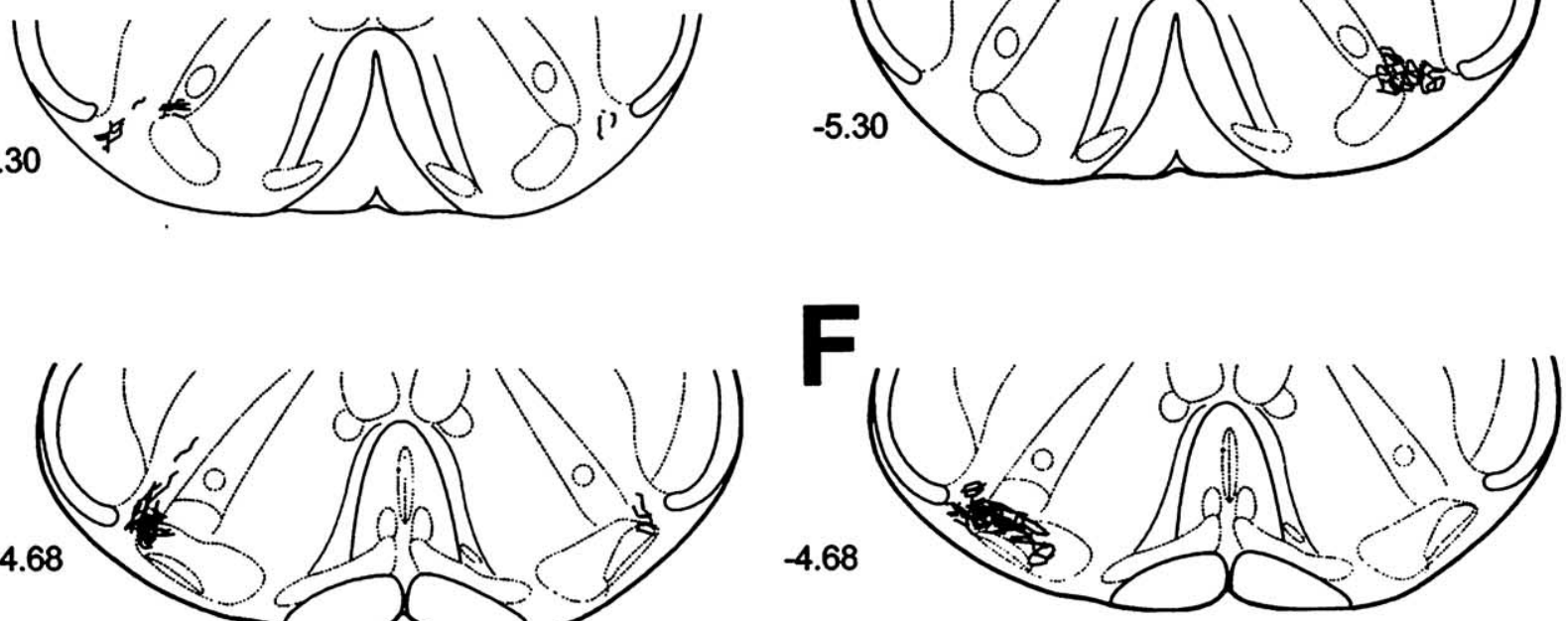

$-4.68$
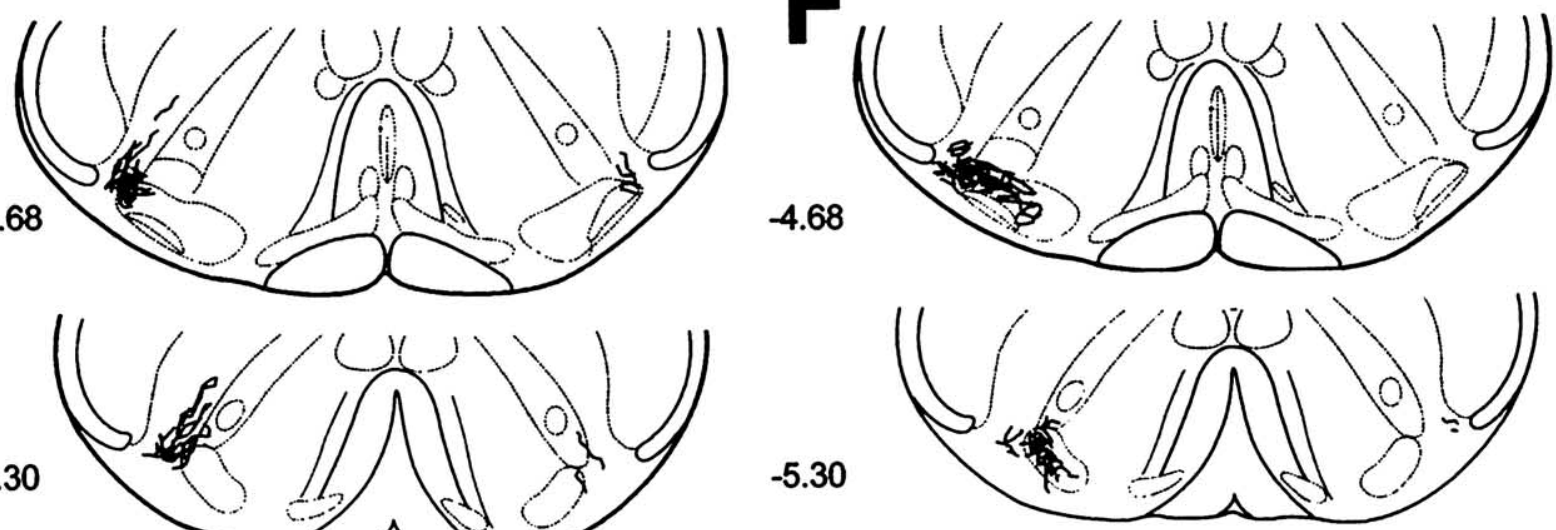

$-5.30$

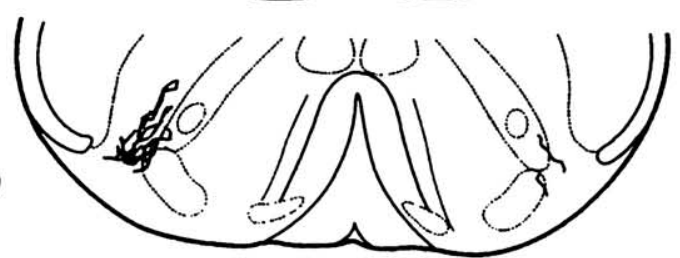

Fig. 5. Diagrams depicting anterograde labeling at the VLM following BDA injections in the LH (A, B), Pa (C), R (D), VLPAG (E) and Lat (F). Each triangle in $A$ corresponds to one noradrenergic neuron of the $A_{1}$ cell group, as seen in an immunostaining for dopamine- $\beta$-hydroxylase (Tavares et al., 1996, 1997a). In B, a photomicrograph of labeled fibers in the VLMlat following an injection in the LH. Arrows in the left corner of B indicate dorsal (D) and lateral (L) directions. Scale bar $=20 \mu \mathrm{m}$.

nociceptive neurons are inhibited by electrical stimulation (Soto-Moyano et al., 1988; Burkey et al., 1996). However, the somatosensory and insular cortices do not target the spinal cord, which indicates that other brain regions mediate cortical-elicited spinal inhibition. Recent data point to a putative role of the medulla oblongata as a possible relay 
of the antinociception produced from those regions. In fact, both telencephalic areas target the DRt and the somatosensory cortex projects, in addition to the RVLM (van Bockstaele and Aston-Jones, 1989; Bernard et al., 1990a; Desbois et al., 1999). The RVLM was shown to inhibit nociceptive spinal neurons (Sidall and Dampney, 1989; Hudson et al., 2000) and the DRt is known to facilitate nociceptive transmission (Almeida et al., 1996, 1999; Lima and Almeida, 2002). The cortical projection to the VLMlat shown in the present study may represent another possible medullary relay in the mediation of the antinociception elicited from the cortex. In a similar manner, the novel pathway from the amygdala to the VLMlat reported in this study may convey the antinociceptive actions from that forebrain region, along with the well-established mediation of the PAG and RMg (Helmstetter et al., 1993a,b; 1998). Ongoing functional experiments will enlighten these questions.

The present data show that the major components of the brainstem endogenous antinociceptive system, namely the PAG, LC, PBN, KF, $A_{5}$ noradrenergic cell group, RMg, Sol and VRt (reviewed by Jones, 1992), are VLMlat afferent sources, suggesting that the VLMlat may play an overall function in pain modulation. The specific role in the so-called analgesic mesolimbic loop formed by the CeA, AcB, lateral BST and PAG (Ma and Han, 1991) of VLMlat afferents remains to be ascertained.

Most regions involved in nociceptive control are also important autonomic centers and the application of a noxious stimulus induces cardiovascular changes (Lovick, 1993). The contribution of the VLMlat to the vasodepression produced from the CVLM was demonstrated by showing that glutamate instillation in the VLMlat decreases blood pressure and heart rate while the opposite occurs after local lesion with quinolinic acid (Tavares et al., 1997b). The neuronal circuitry mediating vasodepression from the CVLM has been described (reviewed by Blessing and Li, 1989; Chalmers and Pilowsky, 1991). Afferents from the Sol activate CVLM neurons, which inhibit the vasopressor center located at the RVLM and, therefore, the excitatory effect exerted by the latter at the thoracic intermediolateral cell collum. It is possible that a similar circuit may be involved in the vasodepression produced from the VLMlat since this region was shown here to be targeted by numerous afferents from the Sol and it projects to the RVLM (McKellar and Loewy, 1982; Woulfe et al., 1990). Functional experiments are necessary to ascertain this possibility. A new area recently emerged at the caudal pole of the RVLM, which mediates cerebrovascular vasodilation and is thus known as the medullary cerebrovascular vasodilatory center (Golanov et al., 2000, 2001). Although this region is in the rostromedial continuation of the VLMlat it is likely that they are different regions. Stimulation of the medullary cerebrovascular vasodilatory center induces rises in blood pressure (Golanov et al., 2000) while the opposite effect is produced from the VLMlat (Tavares et al., 1997b).

Beyond the Sol, several brain areas involved in pain control and autonomic functions send afferents to the
VLMlat. They include the IC, CeA, Pa, LH, PAG, LC, PBN, $K F$, and the $A_{5}$ noradrenergic cell group (Jones, 1992; Tavares and Lima, 2002). It is thus possible that the VLMlat can play a role in the integration of both autonomic and nociceptive functions. This putative integrative function of the VLMlat is further supported by the scarcity of afferents received from autonomic regions that do not participate in pain processing. Among such regions, only the BST was shown to send projections to the VLMlat (Ciriello and Jansen, 1993; Roder and Ciriello, 1993; Davis et al., 1994). In line with the proposed nociceptive/cardiovascular integrative role of the VLMlat, studies showed that hypertension-induced hypoalgesia is conveyed by a VLMlatspinal pathway (Tavares et al., 1997b; Tavares and Lima, 2002).

\section{Motor-related afferents}

The participation of the CVLM in motor functions as been ascribed to the LRt (Clendenin et al., 1974; Alstermark et al., 1981; Ekerot, 1989). In accordance with other tracing studies, our control injections in the LRt showed that it receives massive projections from the main motor-related centers, namely the $\mathrm{R}, \mathrm{IO}$ and cerebellum. Curiously, many of the somatic motor related centers such as the motor cortices, R, IO, Lat and LRt were here shown to send afferent fibers to the VLMlat. Furthermore, the areas involved in visceral motor control, such as the prelimbic and infralimbic cortices (Hurley-Guis and Neafsey, 1986) were also shown to target the VLMlat. Collectively, these data indicate that, in addition to the LRt, the VLMlat may participate in the motor functions performed by the CVLM. Interestingly, afferents from motor-related regions of the brain target both the VLMlat and the LRt. On the contrary, spinal afferents are topographically segregated in the VLM since fibers from the ventral horn target only the LRt while the VLMlat is targeted exclusively by axons from dorsal horn nociceptive layers (laminae I, IV-V; Tavares et al., 1998; Tavares and Lima 2002). The possible meaning of this dual pattern of projections from motor-related centers remains to be ascertained.

\section{Afferents from limbic structures}

The limbic projections to the VLMlat were here shown to have a wider origin that those targeting other medullary regions, namely the Sol (van der Kooy et al., 1982), LRt (Meyer et al., 1986) and DRt (Almeida et al., 2002). The limbic and infralimbic cortices, the CeA and the BST were all shown to send substantial projections to the VLMlat. Besides the classical involvement of the limbic system in motivational-affective responses to pain (Bernard et al., 1990b; Davis, 1992; Roder and Ciriello, 1993; Davis et al., 1994; Johansen et al., 2001), it was proposed that the system forms an emotional-autonomic network that triggers the autonomic changes observed during emotional challenges, such as fear and anxiety (Touzani et al., 1996; Dun and Williams, 1995; Davis, 1998). Since the medullary areas receiving projections from the limbic system are all involved in cardiovascular control, it is likely that the emotional-autonomic network extends to the medulla oblon- 
gata. The inclusion of the VLMlat in that circuit points to its putative involvement in both emotional and cardiovascular reactions to pain.

In summary, the present results indicate that the VLMlat is specially suited to integrate cardiovascular functions, motor activity and affective behavior so that adequate and rapid responses to pain can be produced. The VLMlat may thus play an important role on the protective homeostatic function exerted by the pain system (Melzack and Casey, 1968).

Acknowledgements-This work was supported by FCT project POCTIINSE/38952/2001 and Gulbenkian Pain Program (Portugal).

\section{REFERENCES}

Almeida A, Tjølsen A, Lima D, Coimbra A, Hole K (1996) The medullary dorsal reticular nucleus facilitates acute nociception in the rat. Brain Res Bull 39:7-15.

Almeida A, Cobos A, Tavares I, Lima D (2002) Brain afferents to the medullary dorsal reticular nucleus: a retrograde and anterograde tracing study in the rat. Eur J Neurosci 16:81-95.

Almeida A, Størkson R, Lima D, Hole K, Tjølsen A (1999) The medullary dorsal reticular nucleus facilitates pain behaviour induced by formalin in the rat. Eur $\mathrm{J}$ Neuroci 11:110-122.

Alstermark B, Lundberg A, Norsell U, Sybirska E (1981) Integration of descending motor pathways controlling the forelimb in the cat: IX. Differential behavioral defects after spinal cord lesions interrupting defined pathways from higher motor centers to motoneurones. Exp Brain Res 42:299-318.

Bernard JF, Villanueva L, Carroué J, Le Bars D (1990a) Efferent projections from the subnucleus reticularis dorsalis (SRD): a Phaseolus vulgaris leucoagglutinin study in the rat. Neurosci Lett 116:257-262.

Bernard JF, Huang GF, Besson JM (1990b) Effect of noxious somesthetic stimulation on the activity of neurons in the nucleus centralis of the amygdala. Brain Res 523:347-350.

Blessing WW, Li YW (1989) Inhibitory vasomotor neurons in the caudal ventrolateral region of the medulla oblongata. In: The central neural organization of cardiovascular control (Ciriello J, Caverson MM, Polosa C, eds), pp 83-98. Amsterdam: Elsevier.

Burkey AR, Carsten E, Wenninger JJ, Tang J, Jasmin L (1996) An opioidergic cortical antinociception triggering site in the agranular insular cortex of the rat that contributes to morphine antinociception. J Neurosci 20:6612-6623.

Carstens EE, Watkins LR (1986) Inhibition of neurons in the rat spinal cord to noxious skin heating by stimulation in midbrain periaqueductal gray or lateral reticular formation. Brain Res 382:266-277.

Chalmers J, Pilowsky P (1991) Brainstem and bulbospinal neurotransmitter systems in the control of blood pressure. J Hypertens 9:675694.

Ciriello J, Jansen SA (1993) Effect of chemical stimulation of bed nucleus of the stria terminalis on arterial pressure and heart rate. Am J Physiol 265:H1516-H1522.

Clendenin M, Ekerot CF, Oscarsson O, Rosén I (1974) The lateral reticular nucleus in the cat: II. Organization of component activated from bilateral ventral flexor reflex tract (bVFRT). Exp Brain Res 21:487-500.

Davis M (1992) The role of the amygdala in fear and anxiety. Annu Rev Neurosci 15:353-375.

Davis M, Rainnie D, Cassel M (1994) Neurotrasmission in the rat amygdala related to fear and anxiety. Trends in Neurosciences $17: 208-214$.

Davis M (1998) Are different parts of the extended amygdala involved in fear versus anxiety? Biol Psychiatry 44:1239-1247.

Day TA, Ro A, Renaud LP (1983) Depressor area within caudal ventrolateral medulla of the rat does not correspond to the A1 catecholamine cell group. Brain Res 279:299-302.

Desbois C, Le Bars D, Villanueva L (1999) Organization of cortical projection to the medullary subnucleus reticularis dorsalis: a retrograde and anterograde tracing study in the rat. J Comp Neurol 410:178-196.

Donovick JP (1974) A metachromatic stain for neural tissue. Stain Technol 49:49-51.

Dun JD, Williams TJ (1995) Cardiovascular responses to electrical stimulation of the bed nucleus of the stria terminalis. J Comp Neurol 352:227-234.

Ekerot CF (1989) The lateral reticular nucleus in the cat: VII. Excitatory and inhibitory projection from the ipsilateral forelimb tract (iF tract). Exp Brain Res 79:120-128.

Ericson H, Blomqvist A (1988) Tracing of neuronal connections with cholera toxin subunit B: light and electron microscopic immunohistochemistry using monoclonal antibodies. J Neurosci Methods 24: 225-235.

Gebhart GF, Ossipov MH (1986) Characterization of inhibition of the spinal nociceptive tail-flick reflex in the rat from the medullary latera reticular nucleus. J Neurosci 6:701-713.

Golanov EV, Christensen JRC, Reis DJ (2000) The medullary cerebrovascular vasodilator area mediates cerebrovascular vasodilation and electroencephalogram synchronization elicited from cerebellar fastigial nucleus in Sprague-Dawley rats. Neurosci Lett 288: 183-186.

Golanov EV, Christensen JRC, Reis DJ (2001) Neurons of a limited subthalamic area mediate elevations in cortical cerebral blood flow evoked by hypoxia and excitation of neurons of the rostral ventrolateral medulla. J Neurosci 21:4032-4041.

Harris JA (1996) Descending antinociceptive mechanisms in the brainstem: their role in the animals defensive system. J Physiol 90:15-25.

Helmstetter FJ, Bellgowan PS, Tershner SA (1993a) Lesions of the amygdala block conditional hypoalgesia on the tail flick test. Brain Res 612:253-257.

Helmstetter FJ, Bellgowan PS, Tershner SA (1993b) Modulation of spinal nociceptive reflexes by the microinjection of morphine into the amygdala. Neuroreport 4:471-474.

Helmstetter FJ, Tershner SA, Poore LH, Bellgowan PSF (1998) Antinociception following opioid stimulation of the basolateral amygdala is expressed through the periaqueductal gray and rostral ventromedial medulla. Brain Res 779:104-118.

Hudson PM, Semenenko FM, Lumb BM (2000) Inhibitory effects evoked from the rostral ventrolateral medulla are selective for the nociceptive responses of spinal dorsal horn neurons. Neuroscience 99:541-547.

Hurley-Guis KM, Neafsey EJ (1986) The medial frontal cortex and gastric motility: microstimulation results and their possible significance for the overall pattern of organization of the rat frontal and parietal cortex. Brain Res 365:241-248.

Janss AJ, Gebhart GF (1987) Spinal monoaminergic receptors mediate the antinociception produced by glutamate in the medullary lateral reticular nucleus. J Neurosci 7:2862-2873.

Janss AJ, Gebhart GF (1988) Quantitative characterization and spinal pathway mediating inhibition of spinal nociceptive transmission from the lateral reticular nucleus in the rat. J Neurophysiol 59:226247.

Jensen TS, Yaksh TL (1984) Spinal monoamine and opiate systems partly mediate the antinociceptive effects produced by glutamate at brainstem sites. Brain Res 321:287-297.

Johansen JP, Fields HL, Manning BH (2001) The affective component of pain in rodents: direct evidence for a contribution of the anterior cingulated cortex. Proc Natl Acad Sci USA 98:8077-8082.

Jones SL, Gebhart GF (1986a) Characterization of coeruleospinal inhibition of the nociceptive tail-flick reflex in the rat: mediation by spinal $\alpha_{2}$-adrenoreceptors. Brain Res 364:315-330.

Jones SL, Gebhart GF (1986b) Quantitative characterization of coeru- 
leospinal inhibition of nociceptive transmission in the rat. J Neurophysiol 56:1397-1410.

Jones SL (1992) Descending control of nociception. In: The initial processing of pain and its descending control: spinal and trigeminal system (Gildemberg PL, ed), pp 203-295. Basel: Karger.

Kalia M, Fuxe K (1985) Rat medulla oblongata: I. Cytoarchitectonic considerations. J Comp Neurol 233:285-307.

Kalia M, Fuxe K, Goldstein M (1985) Rat medulla oblongata: II. Dopaminergic, noradrenergic (A1 and A2) and adrenergic neurons, nerve fibers, and presumptive terminal processes. J Comp Neurol 233:308-322.

Kapogianis EM, Flumerfelt BA, Hrycyshyn AW (1982) Cytoarchitecture and cytology of the lateral reticular nucleus in the rat. Anat Embryol 164:229-242.

Koekoek SKE, Ruigrok TJH (1995) Lack of a bilateral projection of individual spinal neurons to the lateral reticular nucleus in the rat: a retrograde, non-fluorescent, double labeling study. Neurosci Lett 200:13-16.

Lima D, Almeida A (2002) The medullary dorsal reticular nucleus as a pronociceptive centre of the pain control system. Progress Neurobiol 66:81-108.

Lima D, Coimbra A (1991) Neurons in the substantia gelatinosa rolandi (lamina II) project to the caudal ventrolateral reticular formation of the medulla oblongata in the rat. Neurosci Lett 132:16-18.

Lima D, Mendes-Ribeiro JA, Coimbra A (1991) The spino-latero-reticular system of the rat: projections from the superficial dorsal horn and structural characterization of marginal neurons involved. Neuroscience $45: 137-152$

Liu RH, Zhao ZQ (1992) Selective blockade by yohimbine of descending spinal inhibition from lateral reticular nucleus but not from locus coeruleus in rats. Brain Res 142:65-68.

Lovick TA (1993) Integrated activity of cardiovascular and pain regulatory systems: role in adaptative behavioural responses. Progress Neurobiol 40:631-644.

Luppi PH, Fort P, Jouvet M (1990) lontophoretic application of unconjugated cholera toxin $\mathrm{B}$ subunit $(\mathrm{CTb})$ combined with immunocytochemistry of neurochemical substances: a method for transmitter identification of retrogradely labelled neurons. Brain Res 534:209_ 224.

Ma QP, Han JS (1991) Neurochemical studies on the mesolimbic circuitry of antinociception. Brain Res 566:95-102.

Melzack R, Casey KL (1968) Sensory, motivational and central control determinants of pain: a new conceptual model. In: The skin senses (Kenshalo DR, ed), pp 423-443. Springfield, IL: Thomas.

Menétrey D, Roudier F, Besson JM (1983) Spinal neurons reaching the lateral reticular nucleus as studied in the rat by retrograde transport of horseradish peroxidase. J Comp Neurol 220:439-452.

Meyer G, Galindo-Mireles D, Gonzalez-Hernandez T, CastaneyraPerdomo A, Ferres-Torres R (1986) Direct projections from the reticular formation of the medulla oblongata to the anterior cingulate cortex in the mouse and the rat. Brain Res 398:207-211.

McKellar S, Loewy AD (1982) Efferent projections of the A1 catecholamine cell group in the rat: an autoradiographic study. Brain Res 241:11-29.

Murugaian J, Sundaram K, Krieger A, Sapru H (1989) Electrolytic lesions in the depressor area of the ventrolateral medulla of the rat abolish depressor responses to the aortic nerve stimulation. Brain Res 499:371-377.

Ness TJ, Gebhart GF (1987) Quantitative comparison of inhibition of visceral and cutaneous spinal nociceptive transmission from the midbrain and medulla in the rat. J Neurophysiol 58:850-865.

Paxinos G, Watson C (1998) The rat brain in stereotaxic coordinates. New York: Academic Press.

Paxinos G (1995) The rat nervous system. Academic Press: San Diego.

Rajakumar N, Hrycyshyn AW, Flumerfelt BA (1992) Afferent organization of the lateral reticular nucleus in the rat: an anterograde tracing study. Anat Embryol 185:25-37.
Roder S, Ciriello J (1993) Contribution of bed nucleus of the stria terminalis to the cardiovascular responses elicited by stimulation of the amygdala. J Autonom Nerv Syst 45:61-75.

Ruigrok TJH, Cella F (1995) Precerebellar nuclei and red nucleus. In: The rat nervous system (Paxinos G, ed), pp 277-308. San Diego: Academic Press.

Saper CB (1995) Central autonomic system. In: The rat nervous system (Paxinos G, ed), pp 107-135. San Diego: Academic Press.

Satoh M, Oku R, Akaike A (1983) Analgesia produced by microinjection of L-glutamate into the rostral ventromedial bulbar nuclei of the rat and its inhibition by intrathecal $\alpha$-adrenergic blocking agents. Brain Res 261:361-364.

Sidall PJ, Dampney RA (1989) Relationship between cardiovascular neurons and descending antinociceptive pathways in the rostral ventrolateral medulla of the rat. Pain 37:347-355.

Snyder RL, Faull RLM, Mehler WA (1978) A comparative study of the neurons of origin of the spinocerebellar afferents in the rat, cat and squirrel monkey based on the retrograde transport of horseradish peroxidase. J Comp Neurol 181:833-852.

Sotgiu ML (1986) Inhibition of the nociceptive jaw opening reflex by the lateral reticular nucleus (LRN) in the rabbit. Neurosci Lett 65:145148.

Soto-Moyano R, Galvez J, Vallejos C, Hernández A (1988) Topical application of morphine to the rat somatomatosensory cortex produces analgesia to tonic pain. J Neurosci Res 19:511-514.

Spyer KM (1989) Neural mechanisms involved in cardiovascular control during affective behaviour. TINS 12:506-513.

Tavares I, Almeida A, Albino-Teixeira A, Lima D (1997b) Lesions of the caudal ventrolatral medulla block the hypertension-induced inhibition of noxious-evoked c-fos expression in the rat spinal cord. Eur J Pain 1:149-160.

Tavares I, Almeida A, Lima D, Coimbra A (1998) The caudal ventrolateral medulla is reciprocally connected with the spinal cord. Soc Neurosci Abstr 24:393.

Tavares I, Lima D (1994) Descending projections from the caudal medulla oblongata to the superficial or deep dorsal horn of the rat spinal cord. Exp Brain Res 99:455-463.

Tavares I, Lima D (2002) The caudal ventrolateral medulla as a major inhibitory center of pain transmission at the spinal cord. J Pain 3:337-346.

Tavares I, Lima D, Coimbra A (1996) The ventrolateral medulla of the rat is connected with the spinal cord dorsal horn an indirect descending pathway relayed in the A5 noradrenergic cell group. J Comp Neurol 374:84-95.

Tavares I, Lima D, Coimbra A (1997a) The pontine A5 noradrenergic cells which project to the spinal cord dorsal horn are reciprocally connected with the caudal ventrolateral medulla in the rat. Eur J Neurosci 9:71-81.

Touzani K, Taghzouti K, Velley L (1996) Cellular organization of lateral hypothalamic efferents to the central amygdaloid nucleus of the rat. Neuroreport 7:517-520.

van Bockstaele E, Aston-Jones G (1989) Diverse afferents converge on the nucleus paragigantocellularis in the rat ventrolateral medulla: retrograde and anterograde tracing studies. J Comp Neurol 290:561-584.

Veenmam CL, Reiner A, Honig MG (1992) Biotinylated dextran amine as an anterograde tracer for single-and double-labeling studies. J Neurosci Methods 41:239-254.

van der Kooy D, McGinty JF, Koda L, Gerfen CR, Bloom FE (1982) Visceral cortex: a direct connection from prefrontal cortex to the solitary nucleus in the rat. Neurosci Lett 33:123-127.

Wouterlood FG, Jorritsma-Byham B (1993) The anterograde neuroanatomical tracer biotynilated dextran amine: comparison with the tracer Phaseolus vulgaris-leucoagglutinin in preparations for electron microscopy. J Neurosci Methods 48:75-87.

Woulfe JM, Flumerfelt BA, Hrycyshyn AW (1990) Efferent connections of the A1 noradrenergic cell group: a DBH immunohistochemical and PHA-L anterograde tracing study. Exp Neurol 109:308-322. 
Yamada J, Otani K (1978) The spinoperiventricular fiber system in the rabbit, rat and cat. Exp Neurol 61:395-406.

Yamada J, Shirao K, Kitamura T, Sato H (1991) Trajectory of spino- cerebellar fibers passing through the inferior and superior cerebellar peduncles in the rat spinal cord: a study using horseradish peroxidase with pedunculotomy. J Comp Neurol 304:147-160.

(Accepted 25 February 2003) 